\title{
Spinal extradural arachnoid cysts: clinical, radiological, and surgical features
}

\author{
James K. Liu, M.D., ${ }^{1}$ Chad D. Cole, M.D., ${ }^{2}$ Peter Kan, M.D., ${ }^{2}$ \\ AND MEIC H. SCHMIDT, M.D. ${ }^{2}$ \\ 'Department of Neurological Surgery, Oregon Health \& Science University, Portland, Oregon; \\ and ${ }^{2}$ Department of Neurosurgery, University of Utah School of Medicine, Salt Lake City, Utah
}

\begin{abstract}
$\checkmark$ Extradural arachnoid cysts in the spine are rare and are seldom a cause of spinal cord compression. They are thought to arise from congenital defects in the dura mater, and they almost always communicate with the intrathecal subarachnoid space through a small defect in the dura. The mainstay of treatment in patients with neurological symptoms is surgical removal of the cyst together with ligation of the communicating pedicle and closure of the dural defect. In the present paper the authors review the literature and discuss the clinical and pathological features, mechanisms of pathogenesis, neuroimaging characteristics, and surgical management of spinal extradural arachnoid cysts. The surgical technique for removal of these lesions is illustrated in a patient with a large thoracolumbar spinal extradural arachnoid cyst causing neurogenic claudication.
\end{abstract}

\section{KEY WORDS • spinal extradural arachnoid cyst • spinal meningeal cyst • neurogenic claudication}

$\mathrm{S}$ PINAL extradural arachnoid cysts are a rare cause of spinal cord compression. ${ }^{1,4,11,15}$ These cysts most commonly occur in the middle to lower thoracic spine $(65 \%)$ but also have been reported in the lumbar and lumbosacral $(13 \%)$, thoracolumbar (12\%), sacral $(7 \%)$, and cervical regions (3\%), ${ }^{3,11,12,14,15}$ Cyst enlargement can result in symptomatic spinal cord compression. . $^{12,15,22}$ Extradural arachnoid cysts develop from protrusions of arachnoid herniating through a small dural defect. The cysts have a pedicle in communication with the spinal subarachnoid space and, because of their origin, contain CSF (Fig. 1). 1,4,6-8,15,16,20,22,24,25 The cause of these cysts has not been determined definitively, although they most probably have a congenital origin. Some may be acquired from trauma, infection, or inflammation. ${ }^{4}$

Magnetic resonance imaging is useful in detecting the mass, and the signal characteristics are consistent with those of CSF. Computed tomography myelography is better for detecting the dural defect when communication between the cyst and the subarachnoid space occurs and thus allows accurate diagnosis of these lesions. Symptomatic cysts are primarily treated with excision and obliteration of the communicating dural defect. In this article, we review the clinical features, pathological features, mechanisms of pathogenesis, neuroimaging characteristics, and surgical management of spinal extradural arachnoid cysts.

\section{Clinical Features}

Spinal arachnoid cysts generally develop in adolescents,

Abbreviations used in this paper: $\mathrm{CSF}=$ cerebrospinal fluid; $\mathrm{CT}=$ computed tomography; $\mathrm{MR}=$ magnetic resonance. and twice as many cases occur in male as in female patients. ${ }^{4}$ Thoracic cysts usually occur in young adolescents, whereas thoracolumbar and lumbar cysts usually appear in adults in the fourth decade of life. ${ }^{4,5}$ These lesions often arise dorsally and can partially protrude into the adjacent neural foramen. A single cyst can extend over several spinal segments, or multiple cysts with separate dural defects and communicating pedicles can compose one lesion. ${ }^{15}$

The location of the cyst within the spine and the severity of spinal cord and root compression affect the clinical presentation. ${ }^{16}$ Spastic tetraparesis and impaired sensory levels are indicative of cervical cysts, whereas Horner syndrome is a common presentation in patients with cysts that occur lower in the cervical spine. ${ }^{4}$ Patients with thoracic cysts tend to present with progressive spastic paraparesis, but back pain is generally uncommon; conversely, patients with lumbar and lumbosacral cysts classically present with low-back pain, radiculopathy, and bowel and bladder dysfunction. Overall, motor weakness is usually more predominant than sensory loss. ${ }^{11,21,25}$ Symptoms can be intermittent and exacerbated by Valsalva maneuvers or gravitational positional forces..$^{24}$ Remissions and fluctuation in symptoms have been reported in approximately $30 \%$ of cases. $^{4}$

\section{Pathological Features}

The wall of a spinal extradural arachnoid cyst usually consists of fibrous connective tissue with an inner singlecell arachnoid lining; however, this lining is sometimes absent on histological examination. ${ }^{11,22}$ Spinal arachnoid cysts have been classified into three major categories: ${ }^{16}$ extradural cysts without spinal nerve root fibers (Type I), 
subdivided into extradural arachnoid cysts (Type IA) and sacral meningoceles (Type IB); extradural cysts with spinal nerve root fibers (Type II); and intradural cysts (Type III). In some cases, an extradural cyst can demonstrate substantial intradural extension. ${ }^{67}$ In nearly all cases of Type IA cysts, communication of CSF between the cyst and the intrathecal subarachnoid space through a dural defect has been reported., ${ }^{4,6,14,16,19}$ The case of a noncommunicating spinal extradural arachnoid cyst was recently reported. ${ }^{13}$ Intraoperatively, the dura was intact and there was no evidence of communication into the intradural subarachnoid space.

\section{Mechanisms of Pathogenesis}

The exact origin and pathogenesis of Type IA spinal extradural arachnoid cysts remain unknown. A congenital origin has been proposed for these cysts, ${ }^{9}$ involving either congenital diverticula of the dura or herniation of arachnoid through a congenital dural defect (Fig. 1). The dural sleeve of the nerve root or the junction of the sleeve and thecal sac are the most common sites for these defects, although less commonly the dorsal midline of the thecal sac is involved. ${ }^{1-4}$ The theory of a congenital origin is further supported by reports of a familial syndrome comprising multiple spinal arachnoid cysts, lower-extremity lymphedema (Milroy disease), and distichiasis (double rows of eyelashes). ${ }^{1,2,15,23} \mathrm{~A}$ genetic component in the origins of spinal extradural arachnoid cysts is also suggested by their association in various cases with congenital pigmented nevi, diastematomyelia, multiple sclerosis, Marfan syndrome, neural tube defects, spinal dysraphism, and syringomyelia., ${ }^{3,19}$ For instance, the loss of tissue elasticity and the decrease in tensile tissue strength associated with Marfan syndrome may be connected with dural ectasia in the development of these cysts. ${ }^{26}$

Cases of spinal arachnoid cysts that clearly do not have a congenital origin have been reported. The association of spinal arachnoid cysts with arachnoiditis, surgery, and trauma has led some authors to suggest that these cysts
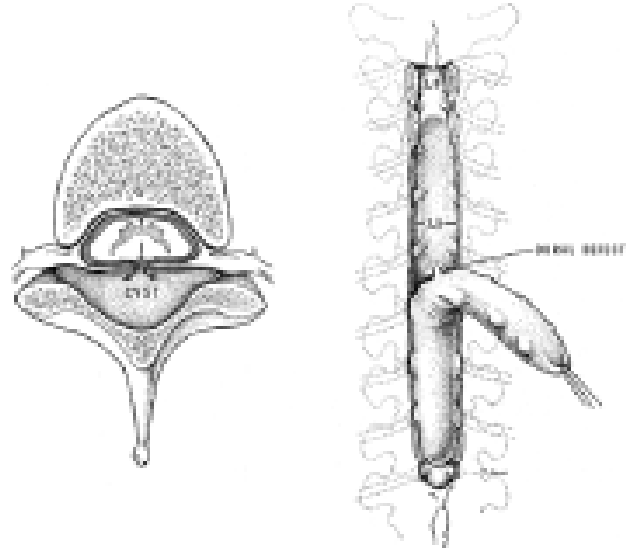

FIG. 1. A: Drawing of a spinal cross section showing a dural defect and cyst communication with the subarachnoid space. B: Drawing of a Type IA spinal, extradural arachnoid cyst with a communicating pedicle at the site of the dural defect. (Reprinted with permission from Bergland RM: J Neurosurg 28: 495-499, 1968).

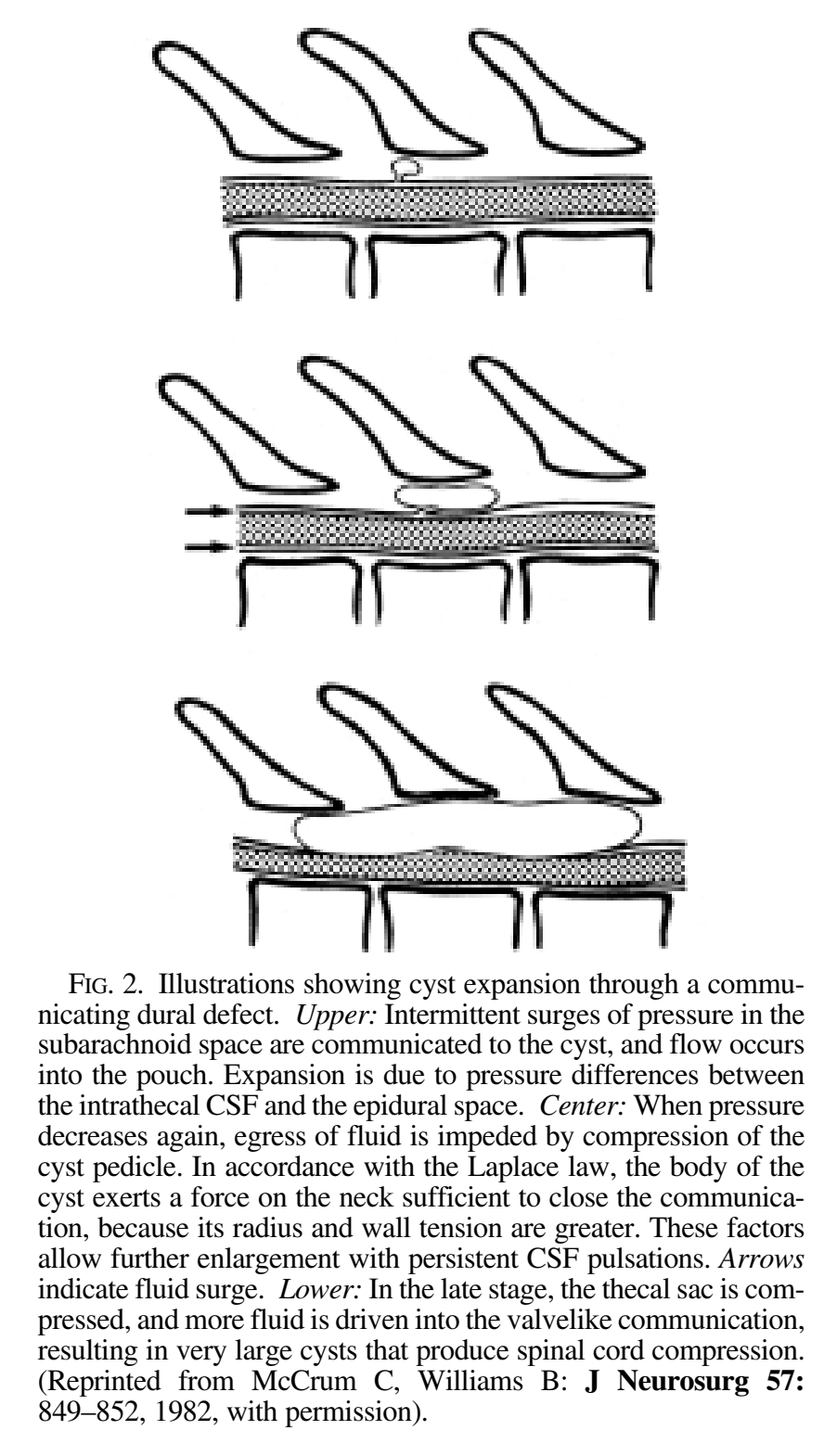

more likely arise from acquired dural defects. ${ }^{21,27}$ Spiegelmann et al. ${ }^{24}$ reported on a case in which hemosiderin-containing macrophages in the cyst wall caused spastic paraparesis 10 years after craniospinal injury.

As with the cyst's initial cause, its mechanism of enlargement leading to spinal cord compression has been a subject of debate. Active fluid secretion from the cyst wall, passive osmosis of water, and hydrostatic pressure of CSF have all been proposed as possible mechanisms for cyst enlargement. ${ }^{11}$ Some authors have postulated that a ball-valve mechanism in the communicating pedicle is associated with pulsatile CSF dynamics and results in cyst expansion. ${ }^{11,14,21}$ According to this theory ${ }_{14}^{14}$ intermittent surges of pressure in the subarachnoid space are communicated to the cyst, and fluid flows into the pouch (Fig. 2). When pressure decreases again, compression of the cyst pedicle inhibits fluid outflow. According to the Laplace law, the cyst body exerts a force on the neck sufficient to close the communication, because its radius and wall ten- 

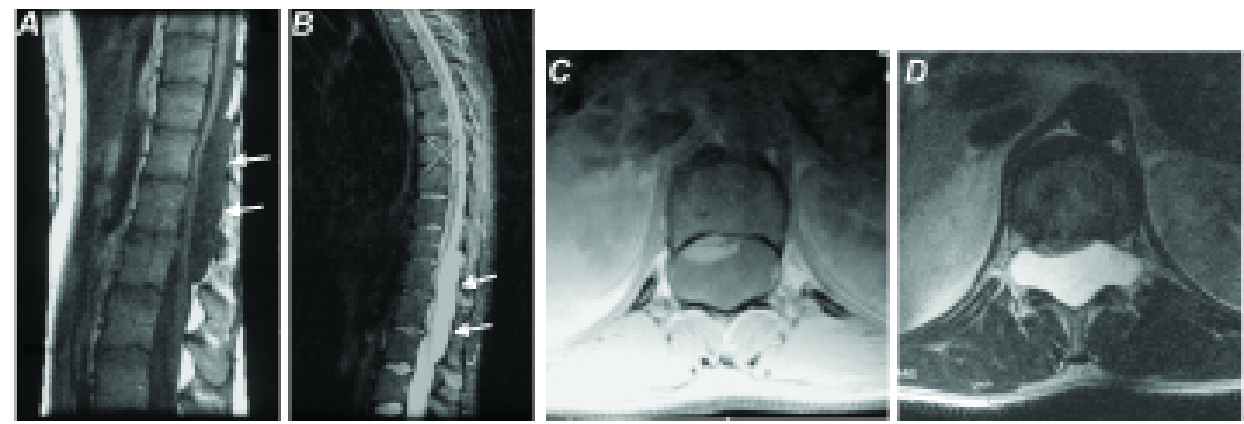

FIG. 3. Sagittal $\mathrm{T}_{1}$-weighted (A) and $\mathrm{T}_{2}$-weighted (B) and axial $\mathrm{T}_{1}$-weighted (C) and $\mathrm{T}_{2}$-weighted (D) MR images obtained in a 20-year-old woman who had presented with 2 months of lower back pain and neurogenic claudication, demonstrating a large spinal extradural arachnoid cyst (white arrows) extending from T-11 to L-2. Note the severe dorsal compression and flattening of the thecal sac. Epidural fat capping can be seen at the superior and inferior poles of the cyst (A). The scalloping and remodeling of the inner osseous margins of the spinal canal with bilateral expansion of the neural foramina is suggestive of longstanding mass effect. There are no obvious communications between the cyst and the intrathecal subarachnoid space, although one is suspected.

sion are greater. These factors then allow further enlargement with persistent CSF pulsations. This ball-valve mechanism has been observed intraoperatively by Rohrer et al. ${ }^{21}$ Bone erosion of the spinal canal may imply the presence of a valve mechanism that is responsible for producing forces of CSF pressure greater than the normal hydrostatic forces within the cyst. ${ }^{16}$

\section{Neuroimaging Features}

Magnetic resonance imaging appears to be effective as an initial modality for diagnosing arachnoid cysts and does not require the intrathecal injection of contrast medium. ${ }^{22}$ It can define the anatomical relationship to surrounding structures. The imaging characteristics of arachnoid cysts are similar to those of CSF signal intensity (Fig. 3). Epidural fat capping of the lesion at its superior and inferior poles can be seen on sagittal $\mathrm{T}_{1}$-weighted MR images, which further suggests its extradural location. The presence of vertebral body scalloping and expansion of the neural foramina bilaterally from osseous remodeling suggests longstanding mass effect from the lesion.

Note, however, that MR imaging may not demonstrate a communication between the cyst and subarachnoid space. Historically, routine water-soluble myelography has been used as the initial study and usually has demonstrated a filling defect at the dural diverticula. ${ }^{16}$ Filling of the cyst through the communicating pedicle may not always be visualized, however, particularly if the patient is placed prone. ${ }^{24}$ The diagnostic study of choice for demonstrating the communication with the subarachnoid space is CT myelography (Fig. 4). Some authors have recommended delayed CT scanning-performed approximately 8 hours after metrizamide myelography-to visualize the communication. ${ }^{8}$ In our practice, we obtain one CT scan immediately after myelography, one 3 hours later, and one the following morning. We have found that delayed CT scanning allows more contrast filling of the cyst for better visualization. Demonstration of this communication allows for an accurate diagnosis of a Type IA spinal extradural arachnoid cyst. Magnetic resonance imaging is valuable in diagnosing a cyst, whereas CT myelography is useful in detecting the communication of the cyst with the subarachnoid space. ${ }^{8,12,15}$ Longstanding hydrostatic pressure within the cyst can cause osseous changes in the spine, such as widening of the interpedicular distance, erosion of the pedicle and posterior elements, scalloping of the posterior aspects of the vertebral bodies, and kyphoscoliosis. ${ }^{8,10}$

\section{Surgical Treatment}

For asymptomatic patients, conservative treatment with observation is recommended. ${ }^{19}$ The mainstay of treatment in patients with symptomatic neurological deterioration from spinal extradural arachnoid cysts is complete excision of the cyst, followed by obliteration of the communicating pedicle and watertight repair of the dural defect to eradicate the ball-valve mechanism (Fig. 5), ${ }^{4,10}$ Total enbloc removal of a large thoracolumbar Type 1A spinal extradural arachnoid cyst is illustrated in Fig. 5. The patient, a 20-year-old woman, had presented with lowback pain and neurogenic claudication (see preoperative images in Figs. 3 and 4). After a T11-L2 laminectomy, the cyst was carefully dissected off the thecal sac, and the communicating pedicle through the dural defect was iden-
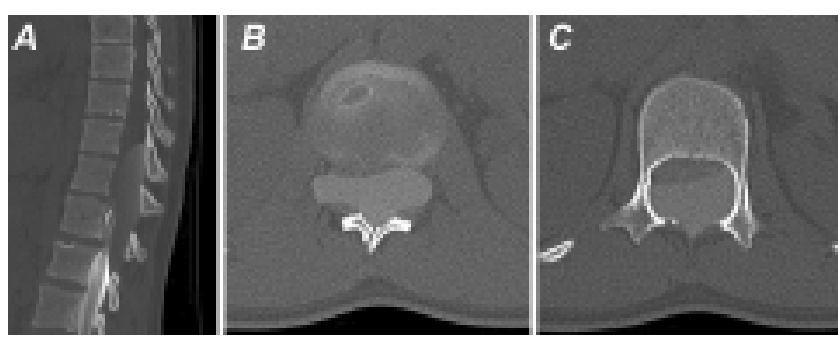

FIG. 4. Sagittal (A) and axial (B and C) delayed CT myelograms obtained in the patient whose images appear in Fig. 3, showing CSF blockage at the middle L-3 level due to a smoothly marginated extradural cyst extending from T-11 to L-2. There is filling of the cyst on these delayed images, which was not seen on the immediate post-CT myelography, suggesting a communication between the thecal sac and the cyst. The conus medullaris and cauda equina are compressed anteriorly. Extensive osseous remodeling and posterior body scalloping are also apparent. The cyst also extends through the neural foramina bilaterally. 

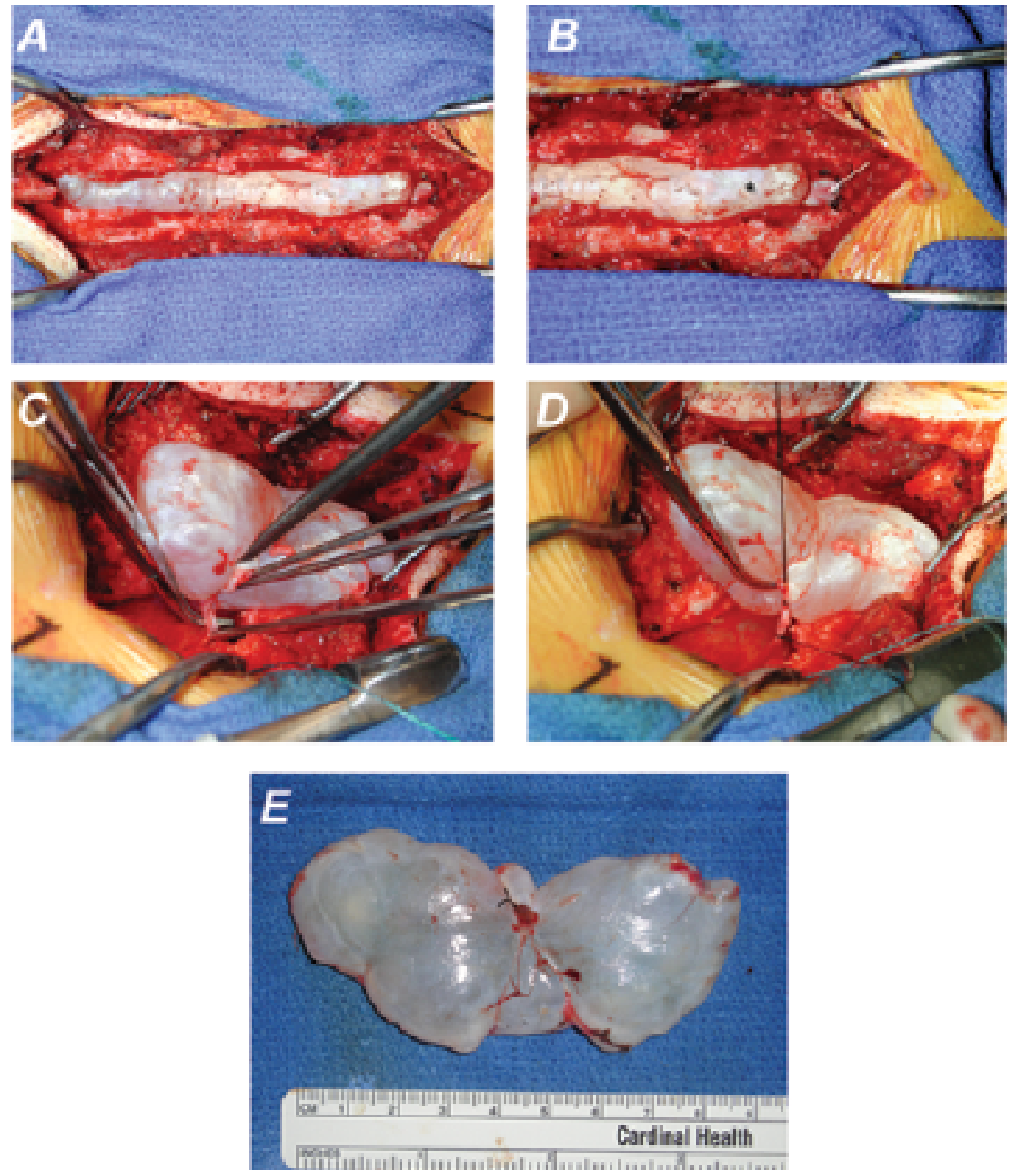

FIG. 5. Intraoperative photographs showing surgical removal of the spinal arachnoid cyst in the patient whose preoperative images are shown in Figs. 3 and 4. A T11-L2 laminectomy was performed to expose the large extradural spinal arachnoid cyst arising from the dorsal aspect of the spinal canal (A). A plane between the cyst (B, asterisk) and thecal sac (white arrow) can be identified to allow dissection of the cyst from the thecal sac for en-bloc removal (C). This technique allows the cyst wall to be kept intact. Careful dissection is performed to decompress the thecal sac, and the dural defect and communicating pedicle in the subarachnoid space are identified. The pedicle is ligated with sutures (D) and divided to allow en-bloc removal of the cyst (E). A suture ligature is seen where the communicating pedicle was tied off (E). The dural defect is then closed primarily and augmented with a dural onlay allograft and fibrin glue. Postoperatively, the patient's symptoms resolved and she was neurologically intact with no evidence of CSF leakage.

tified. The pedicle was ligated with sutures and divided to allow en-bloc removal of the cyst. The dural defect was then oversewn primarily and augmented with a dural onlay allograft and fibrin glue.

Total excision of the cyst is recommended whenever possible to prevent reaccumulation of the cyst. ${ }^{11,17,21,24,25,28}$ These cysts can usually be dissected and elevated off of the dura with ease; however, in cases in which dense fibrous adhesions prevent safe separation of the cyst from the dura, a wide marsupialization of the cyst can be performed by resecting the dorsal wall of the cyst and closing the dural defect. ${ }^{24,25}$ Simple drainage of the cyst contents may result in temporary relief only. If the cyst does not communicate with the subarachnoid space, complete excision can be performed without subsequent repair of the dural defect. Although some authors have advocated cystto-peritoneal shunting when the dural defect is large and not amenable to watertight repair, ${ }^{18,19,23}$ we recommend a trial of patch grafting and fibrin glue repair before considering permanent shunt insertion.

\section{Acknowledgment}

We thank Kristin Kraus for her editorial assistance in preparing this manuscript. 


\section{References}

1. Bergland RM: Congenital intraspinal extradural cyst. Report of three cases in one family. J Neurosurg 28:495-499, 1968

2. Chynn KY: Congenital spinal extradural cyst in two siblings. AJR Am J Roentgenol 101:204-215, 1967

3. Cilluffo JM, Gomez MR, Reese DF, Onofrio BM, Miller RH: Idiopathic ("congenital") spinal arachnoid diverticula. Clinical diagnosis and surgical results. Mayo Clin Proc 56:93-101, 1981

4. Cloward RB: Congenital spinal extradural cysts: case report with review of literature. Ann Surg 168:851-864, 1968

5. Cloward RB, Bucy PC: Spinal extradural cyst and kyphosis dorsalis juvenilis. AJR Am J Roentgenol 38:681-706, 1937

6. Congia S, Coraddu M, Tronci S, Nurchi G, Fiaschi A: Myelographic and MRI appearances of a thoracic spinal extradural arachnoid cyst of the spine with extra- and intraspinal extension. Neuroradiology 34:444-446, 1992

7. Dickson RA, Arabi K, Goodfellow J: Congenital spinal extradural cyst (lateral meningocele) simulating acute transverse myelitis. Report of a case. J Bone Joint Surg Br 60:412-415, 1978

8. DiSclafani A II, Canale DJ: Communicating spinal arachnoid cysts: diagnosis by delayed metrizamide computed tomography. Surg Neurol 23:428-430, 1985

9. Elsberg CA, Dyke CG, Brewer ED: Symptoms and diagnosis of extradural cysts. Bull Neurol Inst NY 3:395-417, 1934

10. Ersahin Y, Yildizhan A, Seber N: Spinal extradural arachnoid cyst. Childs Nerv Syst 9:250-252, 1993

11. Gortvai P: Extradural cysts of the spinal canal. J Neurol Neurosurg Psychiatry 26:223-230, 1963

12. Khosla A, Wippold FJ II: CT myelography and MR imaging of extramedullary cysts of the spinal canal in adult and pediatric patients. AJR Am J Roentgenol 178:201-207, 2002

13. Liu JK, Cole CD, Sherr GT, Kestle JR, Walker ML: Noncommunicating spinal extradural arachnoid cyst causing spinal cord compression in a child. J Neurosurg 103 (3 Suppl): 266-269, 2005

14. McCrum C, Williams B: Spinal extradural arachnoid pouches. Report of two cases. J Neurosurg 57:849-852, 1982

15. Myles LM, Gupta N, Armstrong D, Rutka JT: Multiple extradural arachnoid cysts as a cause of spinal cord compression in a child. Case report. J Neurosurg 91 (1 Suppl):116-120, 1999

16. Nabors MW, Pait TG, Byrd EB, Karim NO, Davis DO, Kobrine
AI, et al: Updated assessment and current classification of spinal meningeal cysts. J Neurosurg 68:366-377, 1988

17. Palmer JJ: Spinal arachnoid cysts. Report of six cases. J Neurosurg 41:728-735, 1974

18. Papo I, Longhi G, Caruselli G: Giant spinal extradural cyst. Surg Neurol 8:350-352, 1977

19. Rabb CH, McComb JG, Raffel C, Kennedy JG: Spinal arachnoid cysts in the pediatric age group: an association with neural tube defects. J Neurosurg 77:369-372, 1992

20. Rengachary SS, O'Boynick P, Karlin CA, Batnitzky S, Price H: Intrasacral extradural communicating arachnoid cyst: cases report. Neurosurgery 8:236-240, 1981

21. Rohrer DC, Burchiel KJ, Gruber DP: Intraspinal extradural meningeal cyst demonstrating ball-valve mechanism of formation. Case report. J Neurosurg 78:122-125, 1993

22. Sato K, Nagata K, Sugita Y: Spinal extradural meningeal cyst: correct radiological and histopathological diagnosis. Neurosurg Focus 13(4): ECP1, 2002

23. Schwartz JF, O'Brien MS, Hoffman JC Jr: Hereditary spinal arachnoid cysts, distichiasis, and lymphedema. Ann Neurol 7: 340-343, 1980

24. Spiegelmann R, Rappaport ZH, Sahar A: Spinal arachnoid cyst with unusual presentation. Case report. J Neurosurg 60: 613-616, 1984

25. Stechison MT, Hendrick EB, Cohen E: Spinal extradural arachnoid cyst. Pediatr Neurosci 15:36-38, 1989

26. Stern WE: Dural ectasia and the Marfan syndrome. J Neurosurg 69:221-227, 1988

27. Swanson HS, Fincher ER: Extradural arachnoid cysts of traumatic origin. J Neurosurg 4:530-538, 1947

28. Zumpano BJ, Saunders RL: Lumbar intradural arachnoid diverticulum with cauda equina compression. Surg Neurol 5: 349-353, 1976

Manuscript submitted November 16, 2006.

Accepted January 8, 2007.

Address reprint requests to: Meic H. Schmidt, M.D., Department of Neurosurgery, University of Utah, 175 North Medical Drive East, Salt Lake City, Utah 84132. email: meic.schmidt@hsc. utah.edu. 